\title{
A Copper-based Fungicide Has Minimal Effects on Tart Cherry Fruit Quantity and Quality
}

\author{
Barrett R. Gruber, Libby R.R. Davies, and Patricia S. McManus ${ }^{1}$ \\ Department of Plant Pathology, University of Wisconsin-Madison, 1630 \\ Linden Drive, Madison, WI 53706
}

Additional index words. abiotic stress, Blumeriella jaapii, cherry leaf spot, disease physiology, phytotoxicity, Prunus cerasus

\begin{abstract}
Copper-based fungicides are effective for managing cherry leaf spot disease incited by Blumeriella jaapii (Rehm) Arx. However, their application has been associated with bronzing discoloration of tart cherry (Prunus cerasus L.) foliage. This work explored the consequences of foliar applications of a copper-based fungicide for tart cherry fruit quantity and quality. 'Montmorency' tart cherry trees were subjected to one of the following fungicide programs in 2007, 2008, and 2009: synthetic fungicides only, synthetic fungicides integrated with a copper-based fungicide, or not sprayed. Each year, the number of fruits per shoot and fruit fresh weight and soluble solids concentration (SSC) were measured three to six times during drupe development. Repeated measures indicated no collection date $\times$ fungicide program effect on the mean number of fruits $(P \geq$ $0.48)$ and SSC $(P \geq 0.14)$ in all years or on fresh weight in 2008 and $2009(P \geq 0.58)$. There was a collection date $\times$ fungicide program effect $(P=0.02)$ on mean fresh weight in 2007 . On 6 July 2007, trees assigned to the integrated copper program were observed having $23 \%$ and $27 \%$ lower fruit fresh weights than trees assigned to the nonsprayed and synthetic programs, respectively. However, pairwise comparisons indicated no difference in fresh weight between the integrated copper and the nonsprayed programs $(P=$ 0.26) and no difference between the integrated copper and synthetic programs $(P=0.25)$ on the final collection date of 2007. In 2007, fresh weight decreased slightly (slope $=-0.08$, $P=0.05)$ as leaf bronzing severity increased, whereas SSC increased slightly (slope $=0.31$, $P=0.06)$. In 2008 and 2009, there was no relationship between bronzing severity and fresh weight or SSC $(P \geq 0.34)$. These results indicate that applied copper does not lead to fewer fruits per shoot or reductions in fresh weight or SSC of mature fruit and that the observed range of leaf bronzing severity had little to no influence on fresh weight and SSC.
\end{abstract}

The fungus Blumeriella jaapii [anamorph Phloeosporella padi (Lib.) Arx] incites cherry leaf spot (CLS), a serious disease of tart cherry (Prunus cerasus) in the Great Lakes region of North America (Jones, 1995) and Europe (Annesi et al., 1997; Lindhard-Pedersen and Hockenhull, 1996). Diseased cherry leaves exhibit necrotic lesions and chlorosis (Jones, 1995; Stanosz, 1992) and low rates of photosynthetic carbon assimilation (Neiderleitner and Knoppik, 1997). The consequences of not managing CLS include premature defoliation that leads to delayed seasonal acclimation of fruit buds and the vascular cambium in the fall and

Received for publication 23 Sept. 2009. Accepted for publication 27 Oct. 2009.

This work was funded by U.S. Department of Agriculture Cooperative State Research, Education and Extension Service project WIS01179.

We thank M. Stasiak, R. Weidman, and B. Schauske for maintaining the orchard block; G. Stanosz and P. Esker for reviewing an early draft of the manuscript; and N. Keuler for statistical consulting.

${ }^{1}$ To whom reprint requests should be addressed; e-mailpsm@plantpath.wisc.edu. spring or tree mortality in winter (Howell and Stackhouse, 1973).

Tart cherry bloom starts in spring from buds on previous years' wood. The cumulative diameter and fresh weight of resulting drupes are consistent with a double sigmoid growth pattern and differ according to the three successive stages (Eisensmith et al., 1980; Flore and Layne, 1999; Tukey, 1934). Stage I encompasses the initial growth of the pericarp; Stage II represents slow growth of the pericarp as the embryo develops; and Stage III characterizes a second and final period of pericarp growth when fruits mature to their harvestable diameter and weight (Flore and Layne, 1999; Tukey, 1934). During Stage III growth, depending on the cultivar, tart cherry pericarps can increase in diameter by $\approx 35 \%$ to $40 \%$ (Tukey, 1934). Fresh weight and soluble solids concentration accumulated by sweet cherry drupes during Stage III have been demonstrated to be dependent on the amount of healthy leaf area per fruit (Roper and Loescher, 1987). The implications of the relationship between healthy leaf area and tart cherry fruit quality were understood in the early 20th century. Keitt et al. (1937) noted that tart cherry fruits from trees that had not been sprayed with fungicides often failed to mature during years when severe CLS symptoms developed early in the season. Therefore, a goal of cherry growers in the Great Lakes region is prevention of CLS symptoms to ensure that fruits mature through Stage III development.

Several foliar synthetic fungicides have been used to control CLS, including benomyl, chlorothalonil, dodine, ferbam, and various sterol demethylation inhibitors (DMIs) and strobilurins. Strains of B. jaapii resistant to benzimidazole fungicides (e.g., benomyl) were detected in the late 1970s (Jones and Ehret, 1980). Subsequently, DMI fungicides have been primarily used because of their excellent control of CLS as well as other diseases such as brown rot and powdery mildew. However, the ability of DMI fungicides to control CLS has been put in jeopardy as a result of the emergence of fungicideresistant strains of B. jaapii (Proffer et al., 2006). Copper-based fungicides, which were widely used for CLS management in the early 1900s (Keitt et al., 1937), are therefore being reintroduced for CLS control (McManus et al., 2007). An appealing feature of copper-based fungicides is their nonspecific mode of action against fungi, which is thought to reduce the likelihood of fungicide resistance (Ware and Whitacre, 2004). McManus et al. (2007) found that incorporating various formulations of copper-based fungicides after bloom into CLS management programs that also relied on the use of synthetic fungicides was as effective in lowering CLS incidence as conventional spray programs that relied exclusively on synthetic fungicides.

Leaf discoloration, variously described as bronzing or necrosis, has been associated with the application of copper-based fungicides to tart cherry (Gruber et al., 2009; Holb and Schnabel, 2005; Keitt et al., 1937; McManus et al., 2007). McManus et al. (2007) concluded that applications of copper-based fungicides did not lead to more defoliation assessed at the time of fruit harvest compared with CLS management programs relying solely on synthetic fungicides. However, the effects of copper-based fungicides on fruit quality are not well understood because reported results are contradictory and the metrics used to evaluate fruit quantity and quality have differed among studies (Holb and Schnabel, 2005; Jamar et al., 2008; Keitt et al., 1937; Lalancette and McFarland, 2007; Palmer et al., 2003). Consequently, the overall aim of the current study was to determine if postbloom applications of copper-based fungicides and leaf bronzing are deleterious to tart cherry fruit. Specific objectives of this study were to: 1 ) monitor the number of fruits per shoot and measure fruit fresh weight and soluble solids concentration (SSC) of fruit from tart cherry trees sprayed with synthetic fungicides only, synthetic fungicides integrated with a copper-based fungicide, or not sprayed; and 2) quantify the relationships between copperassociated leaf bronzing severity and tart cherry fruit fresh weight and SSC. 


\section{Materials and Methods}

Plant material and fungicide applications. Experiments were conducted during 2007, 2008, and 2009 at the University of Wisconsin-Madison Peninsular Agricultural Research Station (UWPARS) in Sturgeon Bay (northeastern Wisconsin, long. $44^{\circ} \mathrm{N}$, lat. $87^{\circ} \mathrm{W}$ ). The experimental orchard of 65 tart cherry trees ('Montmorency' on Prunus mahaleb rootstock) was established in 1995 with tree spacing $7.7 \mathrm{~m}$ within rows and $7.7 \mathrm{~m}$ between rows. Trees were irrigated through a drip irrigation system as needed during all years of the study.

Spray programs are summarized in Table 1. In 2007, the orchard was divided into three blocks, which were randomly assigned to receive one of three fungicide spray programs: 1) nonsprayed control; 2) standard program, which consisted of synthetic fungicides only; or 3) integrated copper program, which consisted of copper sulfate fungicides integrated with synthetic fungicides. In 2008 and 2009, the orchard was divided into six blocks, each block being randomly assigned to one of the three fungicide programs, resulting in each fungicide program being represented twice. Assignment of blocks of trees to fungicide spray programs was rerandomized each year of the study. Fungicides were applied in a volume of $560 \mathrm{~L} \cdot \mathrm{ha}^{-1}$ with an air-blast sprayer to simulate practices used in commercial orchards. Applications were made during calm conditions to minimize fungicide drift between blocks. The first fungicide for each program was applied at or soon after petal fall (15 May 2007, 28 May 2008, and 29 May 2009) with subsequent cover applications made 7 to 17 $\mathrm{d}$ thereafter. The amounts of applied elemental copper differed among years (Table 1), but the application rates were similar to those used commercially (McManus et al., 2007).

Fruit and leaf collections. Tart cherry fruits were collected on six dates in 2007: 14 June, 20 June, 26 June, 6 July, 13 July, and 20 July. Collections started during Stage III of drupe development. In total, three trees from each of the three fungicide spray programs were arbitrarily chosen for fruit and leaf collections and were repeatedly sampled throughout the season. Four terminal shoots were arbitrarily selected per tree on each of the collection dates in 2007 and destructively sampled. All cherry fruits (without peduncles) from the 1-year-old wood of these shoots were harvested. 'Montmorency' tart cherry trees produce $35 \%$ to $68 \%$ of their fruit on 1-year-old wood (Thompson, 1996). The number of fruits and mean cherry fruit fresh weight (grams) for each shoot were recorded. An analog refractometer that was temperaturecompensating (Model BTX-1; VEE GEE Scientific Inc., Kirkland, WA) was used to

Table 1. Fungicide programs applied to 'Montmorency' tart cherry trees at Sturgeon Bay, WI.

\begin{tabular}{|c|c|c|c|c|}
\hline \multirow[b]{2}{*}{ Application date ${ }^{y}$} & \multicolumn{2}{|c|}{ Conventional synthetic program } & \multicolumn{2}{|c|}{ Integrated copper program } \\
\hline & Active ingredient ${ }^{\mathrm{w}}$ & Rate $\left(\mathrm{g} \cdot \mathrm{ha}^{-1}\right)$ & Active ingredient ${ }^{\mathrm{W}}$ & Rate $\left(\mathrm{g} \cdot \mathrm{ha}^{-1}\right)$ \\
\hline \multicolumn{5}{|l|}{2007} \\
\hline 15 May & Chlorothalonil & 3468 & Chlorothalonil & 3468 \\
\hline 30 May & Chlorothalonil & 3468 & Chlorothalonil & 3468 \\
\hline 13 June & $\mathrm{p}+\mathrm{b}^{\mathrm{x}}$ & $126+247$ & Basic copper sulfate & 1961 \\
\hline 22 June & Fenbuconazole & 105 & Basic copper sulfate & 1961 \\
\hline 6 July & $p+b^{x}$ & $107+212$ & Basic copper sulfate & 1961 \\
\hline 16 July & Tebuconazole & 189 & Tebuconazole & 189 \\
\hline 21 Aug. & Chlorothalonil & 3468 & Chlorothalonil & 3468 \\
\hline \multicolumn{5}{|l|}{2008} \\
\hline 28 May & Chlorothalonil & 2626 & Chlorothalonil & 2626 \\
\hline 10 June & Chlorothalonil & 2626 & Chlorothalonil & 2626 \\
\hline 19 June & Fenbuconazole & 105 & Basic copper sulfate & 1345 \\
\hline 26 June & Fenbuconazole & 105 & Basic copper sulfate & 1345 \\
\hline 7 July & $\mathrm{p}+\mathrm{b}^{\mathrm{x}}$ & $94+185$ & Basic copper sulfate & 1345 \\
\hline 21 July & Tebuconazole & 252 & Tebuconazole & 252 \\
\hline 8 Aug. & Chlorothalonil & 3362 & Chlorothalonil & 3362 \\
\hline \multicolumn{5}{|l|}{2009} \\
\hline 29 May & Chlorothalonil & 2689 & Chlorothalonil & 2689 \\
\hline 6 June & Chlorothalonil & 2606 & Chlorothalonil & 2606 \\
\hline 15 June & $\mathrm{p}+\mathrm{b}^{\mathrm{x}}$ & $94+185$ & $\mathrm{p}+\mathrm{b}^{\mathrm{x}}$ & $94+185$ \\
\hline 2 July & Trifloxystrobin & 110 & Basic copper sulfate & 1345 \\
\hline 14 July & Fenbuconazole & 105 & Basic copper sulfate & 1345 \\
\hline 27 July & $\mathrm{p}+\mathrm{b}^{\mathrm{x}}$ & $94+185$ & $p+b^{x}$ & $94+185$ \\
\hline 17 Aug. & Chlorothalonil & 3362 & Chlorothalonil & 3362 \\
\hline
\end{tabular}

${ }^{\mathrm{z}}$ In addition to the synthetic and integrated copper fungicide programs, a nonsprayed control was included ${ }^{y}$ Only one a.i. per fungicide program was applied on each date, unless noted otherwise.

${ }^{\mathrm{x}} \mathrm{p}=$ pyraclostrobin combined with $\mathrm{b}=$ boscalid.

${ }^{w}$ Fungicide common names, brand names, formulations used, and manufacturer: basic copper sulfate (Cuprofix Disperss 20DF; Cerexagri, Inc., King of Prussia, PA, in 2007 and Cuprofix Ultra 40 Disperss in 2008 and 2009); chlorothalonil (Echo 720; Sipcam Agro USA, Inc., Roswell, GA, in 2007, 2008, and 2009 and Equus 720 SST; Makhteshim Agan North America, Inc., Raleigh, NC, in 2009); fenbuconazole (Indar 75WSP; Dow AgroSciences, LLC, Indianapolis, IN); pyraclostrobin + boscalid (Pristine, BASF Corp., Research Triangle Park, NC); tebuconazole (Elite 45DF; Bayer CropScience, Research Triangle Park, NC); trifloxystrobin (Gem 500SC; Bayer CropScience, Research Triangle Park, NC). Amounts of copper refer to metallic copper equivalent applied.

HortScience Vol. 45(1) January 2010 measure the mean cherry fruit SSC (\%) for each shoot. The first, sixth, and 11th (acropetal) fully expanded leaves were harvested from the current year's growth of these same shoots to quantify bronzing symptoms.

In 2008, bloom at the UWPARS orchard was uniformly poor. Therefore, sampling strategies were changed to accommodate the small number of developing fruits. In total, four trees from each of the three fungicide spray programs were arbitrarily chosen for fruit and leaf collections and were repeatedly sampled throughout the season. Fruits were collected on three dates: 25 June, 15 July, and 28 July. Collections started during Stage III of drupe development. Two to 10 shoots per tree were harvested on each date with fewer shoots sampled from trees that had fewer shoots bearing fruit and more shoots sampled from trees that had more shoots bearing fruit. This was done to prevent individual trees from being prematurely removed from the study as a result of oversampling. All cherry fruits (without peduncles) were harvested, counted, and fresh weight and SSC were measured as in 2007. The first and sixth (acropetal) fully expanded leaves were harvested from the current year's growth of these same shoots to quantify bronzing symptoms.

Tart cherry fruits were collected on five dates in 2009: 1 July, 8 July, 16 July, 23 July, and 29 July. Collections started during Stage III of drupe development. In total, four trees from each of the three fungicide spray programs were arbitrarily chosen for fruit and leaf collections and were repeatedly sampled throughout the season as described for 2007. All cherry fruits (without peduncles) were harvested, counted, and fresh weight and SSC were measured as in 2007 and 2008. The first, sixth, and 11th (acropetal) fully expanded leaves were harvested from the current year's growth of these same shoots to quantify bronzing symptoms.

Digital leaf image analysis. Copper-associated leaf bronzing was quantified according to the methods of Erickson et al. (2003) and Gruber et al. (2009) and is briefly described here. Bronzing was present only on the abaxial surfaces of leaves and only on leaves that had been treated with copper-based fungicides. Images of the abaxial surfaces of copper-sprayed leaves were digitized using a flatbed scanner (Epson Perfection 2480 PHOTO; Epson America Inc., Long Beach, CA) at 400 dpi resolution. The images were then individually analyzed using ASSESS image analysis software (Version 1.0; American Phytopathological Society, St. Paul, $\mathrm{MN})$ to calculate the percentage of pixels affected by bronzing. Leaf damage was defined as bronzing of the leaf veins and tissue between veins. Copper-sprayed leaves did not exhibit signs or symptoms related to CLS.

Statistical analyses. All analyses were completed in SAS (Version 9.1.3; SAS Institute Inc., Cary, NC). Data from 2007, 2008, and 2009 were analyzed separately. A mixed model (PROC MIXED) approach to repeated measures analysis (Littell et al., 2006) was used to determine differences in the mean number of 
fruits per shoot, fruit fresh weight, and SSC among fungicide programs at each collection date. Collection date, fungicide program, and their interaction were considered fixed effects. Trees were defined as the experimental units (n $=3$ in 2007 and $n=4$ in 2008 and 2009). The "tree (fungicide)" nested variable was used as the repeated effect in all models to accommodate the covariance of fruits per shoot, fresh weight, and SSC. A compound symmetry covariance structure was used in all years to model number of fruits per shoot collected. The number of fruits per shoot data from 2008 were not normally distributed (AndersonDarling test, $P=0.02$ ), so a natural logarithm transformation was applied. A first-order heterogeneous autoregressive [arh(1)] covariance structure was used for fruit fresh weight and SSC, except for fresh weight means from 2009, which were fitted with an unstructured covariance. An unstructured covariance was used because fitting the $\operatorname{arh}(1)$ structure resulted in an infinite likelihood. The Kenward-Roger correction for degrees of freedom was used in all repeated measures analyses.

Individual trees assigned to each treatment were not spatially randomized because fungicides were applied to blocks of trees. Therefore, to account for possible correlation between individual trees in each year, the "tree (fungicide)" nested variable was added as a random effect to models containing an arh(1) structure to account for possible correlation between individual trees in each year as recommended by Littell et al. (2006). This nested variable was not added to the number of fruits per shoot models or the fresh weight mean model of 2009 because the between-tree variance component was not distinguishable from the compound symmetry and unstructured covariances (Littell et al., 2006). One observation each from the fresh weight data for 2007 and 2008 was deleted as a result of excessively large internally studentized residuals (Cohen et al., 2003). One observation from the SSC data for 2007 was deleted as a result of an excessively large Cook's $D$-statistic (Cohen et al., 2003; Jobson, 1991). Tukey-adjusted multiple pairwise comparisons of all collection date $\times$ fungicide program combinations were used to separate means, when appropriate.

Linear regression was used to quantify the relationship between percentage of leaf surface exhibiting bronzing and cherry fruit fresh weight and SSC separately. Observations from the final collection dates in each year were used. Individual shoots were defined as the experimental units $(\mathrm{n}=12$ in 2007, $\mathrm{n}=32$ in 2008 , and $\mathrm{n}=16$ in 2009). Percentage of leaf surface bronzing ranged from $0.7 \%$ to $5.5 \%$, $0.2 \%$ to $22.0 \%$, and $0.3 \%$ to $6.6 \%$ in 2007 , 2008 , and 2009, respectively. All data from each year were included in the full analyses. However, reduced analyses were conducted to ensure that regressions were calculated over the same range of bronzing severity values for each year. Thus, in 2008, four observations that were greater than $5.5 \%$ and seven observations that were less than $0.7 \%$ were removed from the data set (2008 reduced analysis). In 2009 , two observations that were greater than
$5.5 \%$ and three observations that were less than $0.7 \%$ were removed from the data set (2009 reduced analysis). The "tree" variable was added as a repeated effect to regression models to account for possible shoot-to-shoot correlation. In all cases, this repeated effect did not affect values of Akaike's Information Criterion (Burnham and Anderson, 2002; Littell et al., 2006), so it was removed from all models. One observation each from the fresh weight and SSC data for 2008 (reduced analysis, sample size $n=20$ ) was deleted as a result of excessively large internally studentized residuals. Fruit fresh weight data from the 2009 reduced analysis were not normally distributed (Anderson-Darling test, $P=0.04$ ); therefore, a natural logarithm transformation was applied to those data before analysis. All regression models were evaluated using PROC MIXED and final models were rerun in PROC REG to obtain coefficient of determination values.

\section{Results}

Effect of fungicide programs on number of tart cherry fruits per shoot and fruit quality. There was no interaction between collection date and fungicide program on mean number of fruits per shoot in any year (Fig. 1).
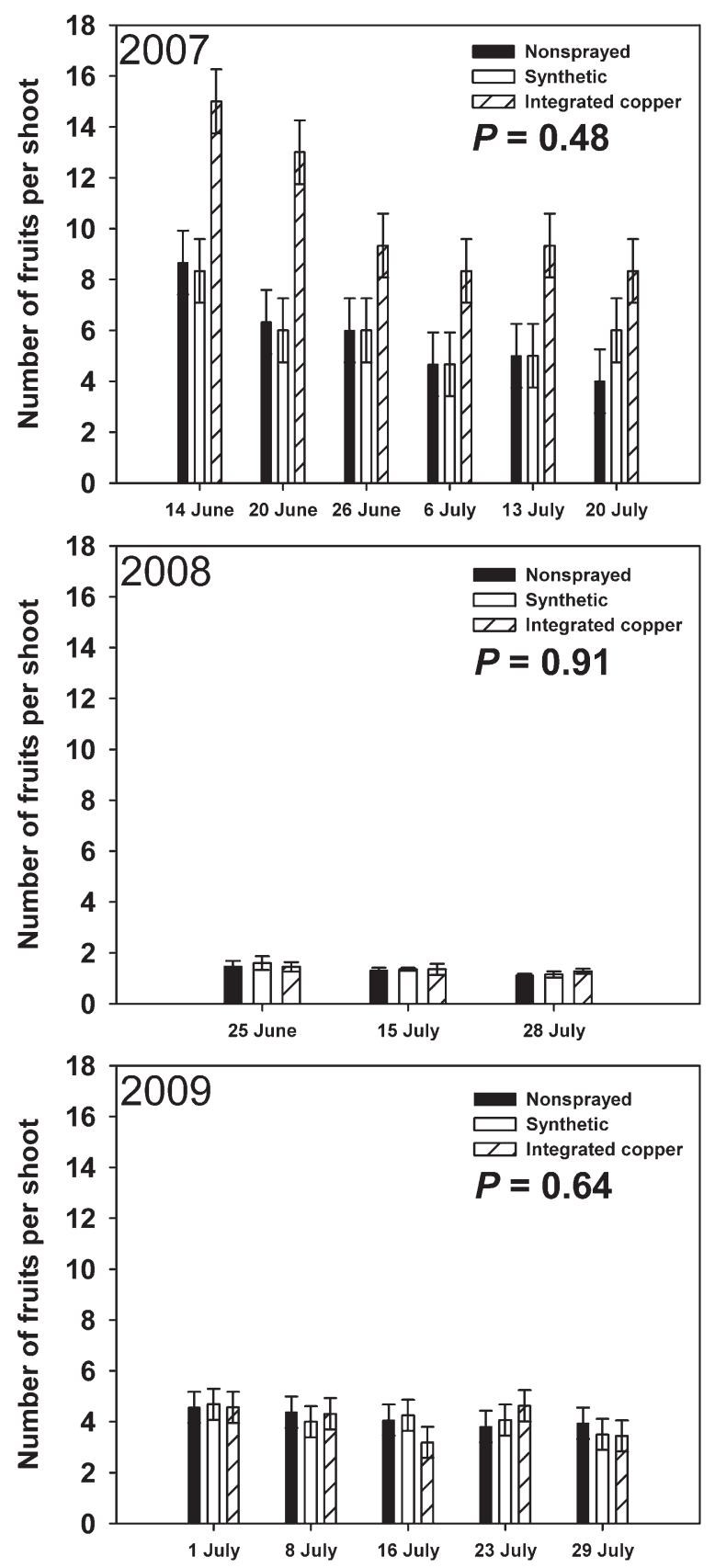

Fig. 1. Effect of fungicide program on number of tart cherry fruits per terminal shoot. Data are means $( \pm 1$ $\mathrm{SE})$. Trees were considered experimental units. Sample sizes for each fungicide program at each collection date were $n=3$ (2007) and $n=4$ (2008 and 2009). Data were analyzed using repeated measures. $P$ values signify the collection date $\times$ fungicide program interaction fixed effect. The $P$ value in 2008 corresponds to a natural logarithmic transformation, but untransformed means are shown. 
Although number of fruits was unaffected by fungicide program, it varied among years (Fig. 1).

There was an interaction $(P=0.02)$ between collection date and fungicide program on mean cherry fruit fresh weight values among the three programs during 2007 (Fig. 2). On 6 July 2007, fruit fresh weight was lower in trees assigned to the integrated copper spray program by $23 \%(P=0.03)$ and $27 \%(P=0.01)$ compared with the non- sprayed and synthetic programs, respectively. Tukey-adjusted pairwise comparisons of all collection date $\times$ fungicide program combinations revealed that 6 July 2007 was the only date when there was a significant difference in mean fresh weights among the fungicide programs. On the final collection date in 2007 (20 July), there was no difference in fresh weight of fruit between the integrated copper and nonsprayed programs $(P=0.26)$ and integrated copper and synthetic programs $(P=0.25)$.
There was no interaction between collection date and fungicide program on mean fresh weight in $2008(P=0.58)$ and 2009 $(P=0.92)$. There was no interaction between collection date and fungicide program on mean SSC values in any year (Fig. 2).

Effect of copper-associated leaf bronzing on tart cherry fruit fresh weight and soluble solids concentration. Leaf bronzing severity ranged from $0.7 \%$ to $5.5 \%$ in 2007 (Fig. 3). In 2008 , the range of leaf bronzing severity was
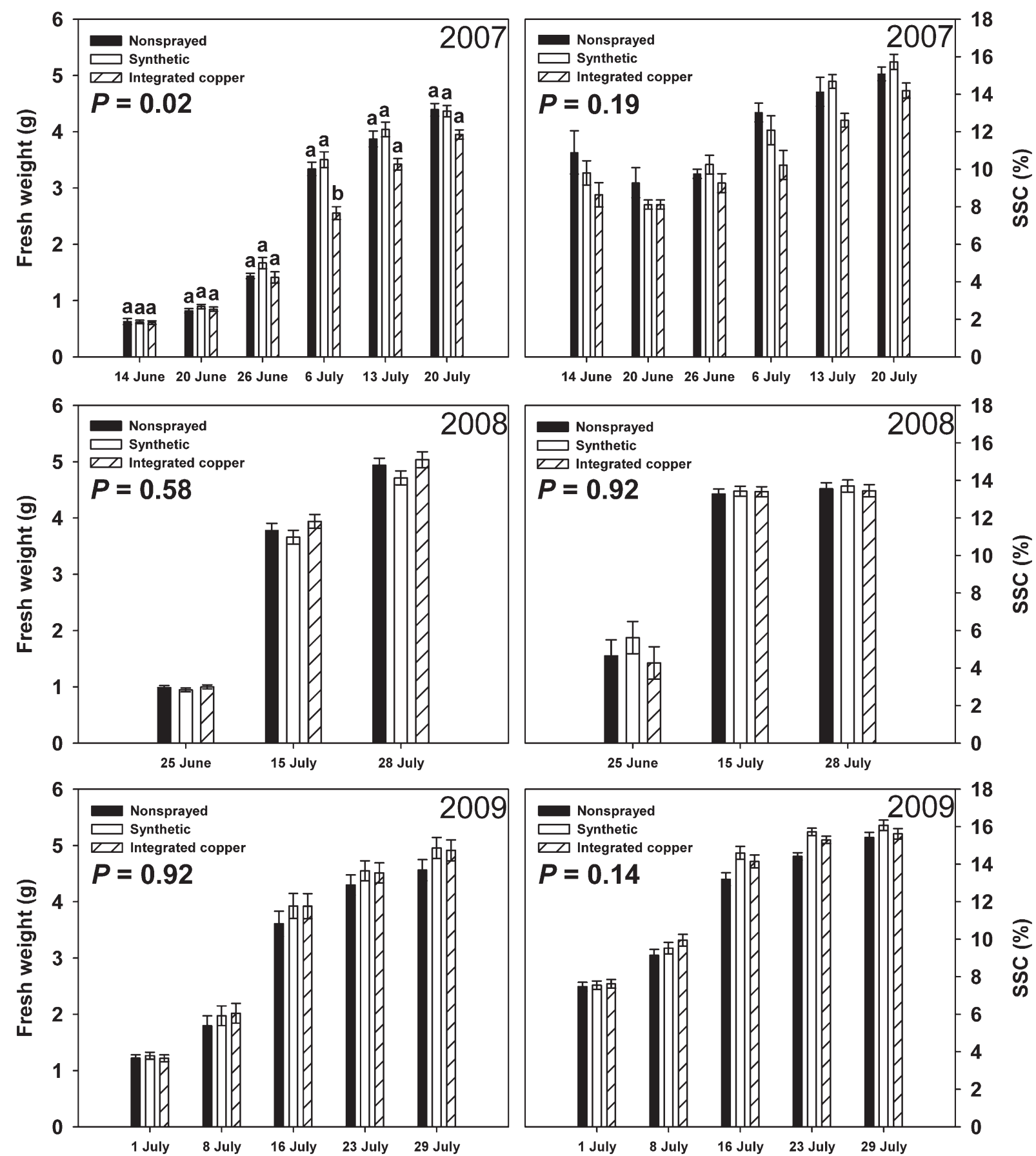

Fig. 2. Effect of fungicide program on tart cherry fruit fresh weight and soluble solids concentration (SSC). Data are means ( $\pm 1 \mathrm{SE})$. Trees were considered experimental units. Sample sizes for each fungicide program at each collection date were $n=3$ (2007) and $n=4$ (2008 and 2009). Exceptions to sample sizes for fresh weight data: synthetic program, 6 July 2007, $\mathrm{n}=2$; integrated copper program 28 July 2008, $\mathrm{n}=3$. Exceptions to sample sizes for SSC data: nonsprayed program, 20 June $2007, \mathrm{n}=2$. Data were analyzed using repeated measures. Tukey-adjusted multiple pairwise comparisons were used to separate means. $P$ values signify the collection date $\times$ fungicide program interaction fixed effect. Means labeled with the same letter on a given collection date are not significantly different $(P>0.05)$. 

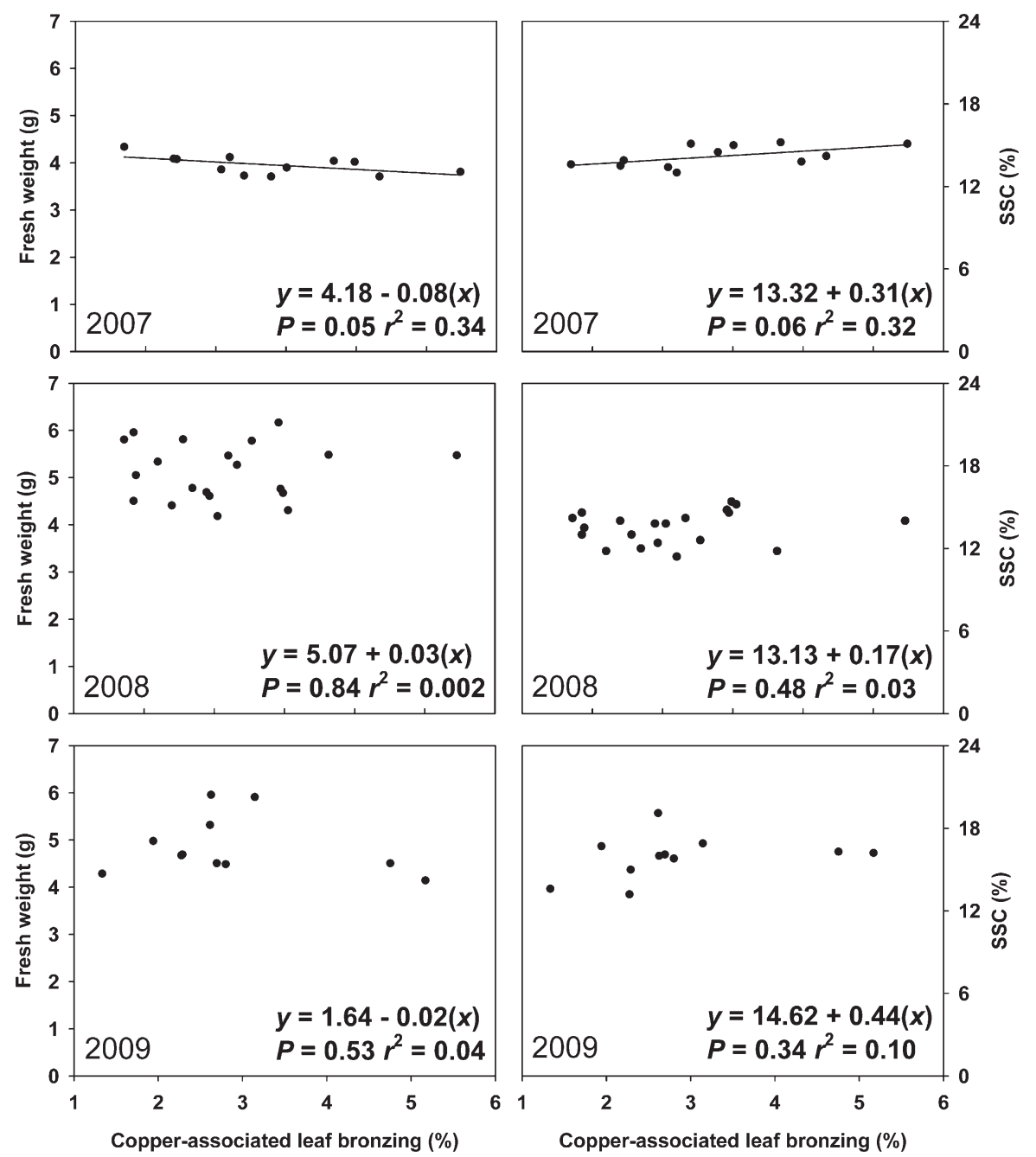

Fig. 3. Effect of copper-associated leaf bronzing severity on tart cherry fruit fresh weight and soluble solids concentration (SSC). Data are from the last collection date in each year: 20 July 2007, 28 July 2008 (reduced analysis), and 29 July 2009 (reduced analysis). Bronzing severity ranges from $0 \%$ to $6 \%$ on the $\mathrm{x}$-axes for 2007 and 2008. Each point represents one shoot average of bronzing severity and its corresponding average of fresh weight or SSC. Sample sizes at each collection date were $\mathrm{n}=12(2007)$ $\mathrm{n}=20$ (2008), and $\mathrm{n}=11$ (2009). Data were analyzed using simple linear regression and $P$ values represent the significance of slope estimates. The regression equation and $P$ value for fresh weight data in 2009 correspond to a natural logarithmic transformation, but untransformed data are shown. Solid lines represent fitted values.

from $0.2 \%$ to $22.0 \%$ in the full analysis (not shown) and $0.7 \%$ to $5.5 \%$ in the reduced analysis (Fig. 3). In 2009, the range of leaf bronzing severity was from $0.3 \%$ to $6.6 \%$ in the full analysis (not shown) and $1.3 \%$ to $5.2 \%$ in the reduced analysis (Fig. 3). In 2007, leaf bronzing severity was associated with slightly decreased (slope $=-0.08, P=$ $0.05)$ fruit fresh weight. Conversely, SSC increased slightly as the severity of leaf bronzing increased (slope $=0.31, P=0.06$ ) In 2008 , the full analysis revealed that copper-associated leaf bronzing did not affect fruit fresh weight (slope $=0.03, P=0.34$ ) or SSC (slope $=-0.02, P=0.74)$ (data not shown). The 2008 reduced analysis revealed that leaf bronzing did not affect fresh weight $(P=0.84)$ or SSC $(P=0.48)$ (Fig. 3). In 2009, the full analysis revealed that copper-associated leaf bronzing did not affect fruit fresh weight (slope $=0.03, P=0.70)$ or SSC (slope $=0.32$, $P=0.12$ ) (data not shown). The 2009 reduced development compared with the standard, synthetic program, or nonsprayed control. Moreover, linear regression analysis revealed that bronzing severity, which ranged from $0.0 \%$ to $0.27 \%$ (median $=0.02 \%$ ), had no impact on fruit fresh weight (slope $=-1.9$, $P=0.09$ ) on 6 July 2007 , the single collection date when cherry fresh weights from the integrated copper program were observed to be lower than those of the other fungicide programs (data not graphed). Likewise, Lalancette and McFarland (2007) incorporated azoxystrobin and tebuconazole fungicides into a copper-based fungicide program but did not observe effects on fruit weight of peach and nectarine compared with controls.

There have been mixed consequences for fruit quality described in studies investigating the sole use of copper-based fungicides or combinations of copper and sulfur. From 1932 to 1935, Keitt et al. (1937) evaluated exclusive and serial applications of Bordeaux mixture (copper sulfate and lime) over multiple years on tart cherry fruit quality and concluded that, compared with applications of a lime-sulfur mixture, Bordeaux sprays did not lead to lower fruit weights. Holb and Schnabel (2005) reported that two or three applications of copper hydroxide to tart cherry during the bloom period for control of brown rot caused stunting and necrosis of spur-leaf clusters. Nevertheless, yield was greater on copper-sprayed trees than in nonsprayed trees in a wet year, probably because copper lowered the incidence of brown rot. In the current study, CLS signs and symptoms appeared only on leaves collected from the nonsprayed control program and therefore did not confound comparisons between the standard synthetic and integrated copper spray programs. Median severity of foliar CLS symptoms in the nonsprayed program was low: $0.4 \%, 0.0 \%$, and $0.0 \%$ of leaf surface affected on the final collection dates in 2007, 2008, and 2009, respectively. Combined foliar applications of sulfur and copper have been associated with greater apple ('Reinette des Capucins') yield compared with nonsprayed controls in the absence of significant scab disease pressure (Jamar et al., 2008). Those authors offered that foliar application of sulfur-based fungicides may aid in overcoming deficiencies of this nutrient as an explanation for increased yield responses, but they did not provide a reason for any direct benefits of copper.

The published reports do not provide a clear picture as to how copper-based fungicides affect fruit SSC. Copper-based fungicides did not affect SSC of mature fruits in the current study. However, Palmer et al. (2003) noted inconsistent effects of a copper hydroxide fungicide on SSC of 'Braeburn' apple fruit between two harvest dates, but those authors did not provide an explanation for the inconsistency. In addition, applications of sulfur-based fungicides also have produced inconsistent effects on peach fruit SSC compared with controls (Schnabel and Layne, 2004; Schnabel et al., 2007). Schnabel et al. (2007) noted that cultivar choice may 
have contributed to the varying effects of sulfur application on SSC of peach. The present study included only 'Montmorency' tart cherry trees because this cultivar accounts for greater than $90 \%$ of tart cherry production in North America.

Identifying the links between the applications of copper-based pesticides, subsequent leaf discoloration, and quantifying the relationships between leaf discoloration and fruit quality have not been exhaustively pursued. In the present investigations, leaf bronzing had a minor negative effect on fresh weight in 2007 , but no relationships were observed in 2008 and 2009. Leaf bronzing was not detrimental to tart cherry fruit SSC in any years. Thus, based on the results of this study, copper-associated leaf bronzing has little, if any, impact on tart cherry fresh weight and SSC. However, the appearance of leaf bronzing is visually alarming for most growers and research focusing on the etiology and mitigation of this discoloration may be warranted.

In conclusion, applying basic copper sulfate to tart cherry during fruit development has minimal effects on the quantity and quality of mature fruits. On the other hand, the devastating effects of CLS on leaf physiology (Neiderleitner and Knoppik, 1997) and on fruit yield and quality (Jones, 1995; Keitt et al., 1937) have been demonstrated. Thus, the benefits of fungicide resistance management and disease control that are achieved through an integrated copper spray program are likely to be greater than the minimal effects of copper sulfate-based fungicides on tart cherry fruit quality.

\section{Literature Cited}

Annesi, T., E. Motta, and E. Forti. 1997. First report of Blumeriella jaapii teleomorph on wild cherry in Italy. Plant Dis. 81:1214.

Burnham, K.P. and D. Anderson. 2002. AIC differences, $\Delta_{i}$, p. 70-71. In: Model selection and multimodel inference: A practical informationtheoretic approach. 2nd Ed. Springer-Verlag, New York, NY.

Cohen, J., P. Cohen, S.G. West, and L.S. Aiken. 2003. Influence on the regression estimates, p. 404. In: Applied multiple regression/correlation analysis for the behavioral sciences. 3rd Ed. Lawrence Erlbaum Associates, Mahwah, NJ.
Eisensmith, S.P., A.L. Jones, and J.A. Flore. 1980. Predicting leaf emergence of 'Montmorency' sour cherry from degree-day accumulations. J. Amer. Soc. Hort. Sci. 105:75-78.

Erickson, J.E., G.R. Stanosz, and E.L. Kruger. 2003. Photosynthetic consequences of Marssonina leaf spot differ between two poplar hybrids. New Phytol. 161:577-583.

Flore, J.A. and D.R. Layne. 1999. Photoassimilate production and distribution in cherry. HortScience 34:1015-1019.

Gruber, B.R., L.R.R. Davies, E.L. Kruger, and P.S. McManus. 2009. Effects of copper-based fungicides on foliar gas exchange in tart cherry. Plant Dis. 93:512-518.

Holb, I.J. and G. Schnabel. 2005. Effect of fungicide treatments and sanitation practices on brown rot blossom blight incidence, phytotoxicity, and yield for organic sour cherry production. Plant Dis. 89:1164-1170.

Howell, G.S. and S.S. Stackhouse. 1973. The effect of defoliation time on acclimation and dehardening in tart cherry (Prunus cerasus L.). J. Amer. Soc. Hort. Sci. 98:132-136.

Jamar, L., B. Lefrancq, C. Fossotte, and M. Lateur. 2008. A during-infection spray strategy using sulphur compounds, copper, silicon, and a new formulation of potassium bicarbonate for primary scab control in organic apple production. Eur. J. Plant Pathol. 122: 481-493.

Jobson, J.D. 1991. Influence, outliers and leverage, p. 158-159. In: Casella, G., S. Fienburg, and I. Olkin (eds.). Applied multivariate data analysis. Springer-Verlag, New York, NY.

Jones, A.L. 1995. Cherry leaf spot, p. 21-22. In: Ogawa, J.M., E.I. Zehr, G.W. Bird, D.F. Ritchie, K. Uriu, and J.K. Uyemoto (eds.). Compendium of stone fruit diseases. Amer. Phytopathol. Soc., St. Paul, MN.

Jones, A.L. and G.R. Ehret. 1980. Resistance of Coccomyces hiemalis to benzimidazole fungicides. Plant Dis. 64:767-769.

Keitt, G.W., E.G. Blodgett, E.E. Wilson, and R.O. Magie. 1937. The epidemiology and control of cherry leaf spot. Wisc. Agr. Expt. Sta. Res. Bul. 132.

Lalancette, N. and K.A. McFarland. 2007. Phytotoxicity of copper-based bactericides to peach and nectarine. Plant Dis. 91:1122-1130.

Lindhard-Pedersen, H. and J. Hockenhull. 1996. Effects of urea on the formation of apothecia and winter conidia of Blumeriella jaapii (cherry leaf spot) and associated microfungi on overwintered cherry leaves. Gartenbauwissenschaft 61:257-261.

Littell, R.C., G.A. Milliken, W.W. Stroup, R.D. Wolfinger, and O. Schabenberger. 2006. Anal- ysis of repeated measures data, p. 159-204. In: SAS for mixed models. 2nd Ed. SAS Inst., Cary, NC.

McManus, P.S., T.J. Proffer, R. Berardi, B.R. Gruber, J.E. Nugent, G.R. Ehret, Z. Ma, and G.W. Sundin. 2007. Integration of copperbased and reduced-risk fungicides for control of Blumeriella jaapii on sour cherry. Plant Dis. 91:294-300.

Niederleitner, S. and D. Knoppik. 1997. Effects of the cherry leaf spot pathogen Blumeriella jaapii on gas exchange before and after expression of symptoms on cherry leaves. Physiol. Mol. Plant Pathol. 51:145-153.

Palmer, J.W., S.B. Davies, P.W. Shaw, and J.N. Wünsche. 2003. Growth and fruit quality of 'Braeburn' apple (Malus domestica) trees as influenced by fungicide programmes suitable for organic production. N. Z. J. Crop Hortic. Sci. 31:169-177.

Proffer, T.J., R. Berardi, Z. Ma, J.E. Nugent, G.R. Ehret, P.S. McManus, A.L. Jones, and G.W Sundin. 2006. Occurrence, distribution, and polymerase chain reaction-based detection of resistance to sterol demethylation inhibitor fungicides in populations of Blumeriella jaapii in Michigan. Phytopathology 96: 709-717.

Roper, T.R. and W.H. Loescher. 1987. Relationships between leaf area per fruit and fruit quality in 'Bing' sweet cherry. HortScience 22: 1273-1276.

Schnabel, G. and D.R. Layne. 2004. Comparison of reduced-application and sulfur-based fungicide programs on scab intensity, fruit quality, and cost of disease control on peach. Plant Dis. 88:162-166.

Schnabel, G., D.R. Layne, and I.J. Holb. 2007. Micronised and non-micronised sulphur applications control peach scab equally well with negligible differences in fruit quality. Ann. Appl. Biol. 150:131-139.

Stanosz, G.R. 1992. Effect of cherry leaf spot on nursery black cherry seedlings and potential benefits from control. Plant Dis. 76:602604.

Thompson, M. 1996. Flowering habit of sweet and sour cherries, p. 223. In: Webster, A.D. and N.E. Looney (eds.). Cherries: Crop physiology, production, and uses. CAB Intl., Wallingford, UK.

Tukey, H.B. 1934. Growth of the embryo, seed, and pericarp of the sour cherry (Prunus cerasus) in relation to season of fruit ripening. Proc. Amer. Soc. Hort. Sci. 31:125-144.

Ware, G.W. and D.W. Whitacre. 2004. Copper, p. 158-159. In: The pesticide book. 6th Ed. MeisterPro Press, Willoughby, $\mathrm{OH}$ 